\title{
Maximization of Fructooligosaccharides and $\beta$-Fructofuranosidase Production by Aspergillus japonicus under Solid-State Fermentation Conditions
}

\author{
Solange I. Mussatto • Lina F. Ballesteros • \\ Silvia Martins • Dulce A. F. Maltos • \\ Cristóbal N. Aguilar • José A. Teixeira
}

Received: 16 January 2012 / Accepted: 23 April 2012

(C) Springer Science+Business Media, LLC 2012

\begin{abstract}
The conditions of temperature, moisture content, and inoculum rate able to maximize the production of fructooligosaccharides (FOS) and $\beta$-fructofuranosidase (FFase) enzyme by solid-state fermentation were established. Fermentation assays were performed using the support material (coffee silverskin) moistened to 60,70 , or $80 \%$ with a 240 -g/l sucrose solution and inoculated with a spore suspension of Aspergillus japonicus to obtain $2 \times 10^{5}, 2 \times 10^{6}$, or $2 \times 10^{7}$ spores/gram dry material. The fermentation runs were maintained under static conditions at 26,30 , or $34{ }^{\circ} \mathrm{C}$ during $20 \mathrm{~h}$. The moisture content did not influence the FOS and FFase production; however, temperature between 26 and $30^{\circ} \mathrm{C}$ and inoculum rate of approximately $2 \times 10^{7}$ spores/gram dry material maximized the results $(\mathrm{FOS}=208.8 \mathrm{~g} / \mathrm{l}$ with productivity of $10.44 \mathrm{~g} / \mathrm{l} \mathrm{h}$; FFase $=64.12$ units $\mathrm{U} / \mathrm{ml}$ with productivity of $4.0 \mathrm{U} / \mathrm{ml} \mathrm{h}$ ). These results are considerably higher than those obtained under no optimized fermentation conditions and represent an important contribution for the establishment of a new industrial process for FOS and FFase production.
\end{abstract}

S. I. Mussatto $(\square) \cdot$ L. F. Ballesteros $\cdot S$. Martins $\cdot$ J. A. Teixeira Institute for Biotechnology and Bioengineering (IBB),

Centre of Biological Engineering, University of Minho, Campus Gualtar,

4710-057 Braga, Portugal

e-mail: solange@deb.uminho.pt

S. I. Mussatto

e-mail: solangemussatto@hotmail.com

D. A. F. Maltos · C. N. Aguilar

Food Research Department, School of Chemistry,

Autonomous University of Coahuila,

Blvd. Venustiano Carranza S/N Col. República Oriente,

25280 Saltillo, Coahuila, Mexico
Keywords Coffee silverskin · Solid-state fermentation · Fructooligosaccharides $\cdot \beta$-Fructofuranosidase $\cdot$ Aspergillus japonicus

\section{Introduction}

Fructooligosaccharides (FOS), also known as oligofructose or oligofructan, are oligosaccharides that can be used as artificial or alternative sweeteners and are considered small dietary fibers with low caloric value. Additionally, FOS has important functional properties due to its capacity of serving as substrate for microflora in the large intestine, increasing the gastrointestinal tract health. FOS also promotes calcium and magnesium absorption in animals and the human gut, and decreases the levels of phospholipids, triglycerides, and cholesterol (Yun 1996; Hartemink et al. 1997; Van den Heuvel et al. 1999; Mussatto and Mancilha 2007).

FOS is mainly produced on industrial scale from disaccharide sucrose by microbial enzymes with transfructosylating activity ( $\beta$-fructofuranosidases (FFase) EC.3.2.1.26, also designed as fructosyltransferases EC.2.4.1.9). The main drawback of this commercial process is that the yields are normally low (55-60 \%) (Yun 1996; Nishizawa et al. 2001). Therefore, and due to the increased use of this ingredient in food and pharmaceutical products, the development of a suitable and economically viable process that allows obtaining FOS on industrial scale with higher yields and productivities has been strongly encouraged. Among the variety of fungal strains in which FFase enzymes have been found, Aspergillus japonicus has been reported as being potentially adequate for industrial production of FOS and FFase (Chien et al. 2001; Mussatto et al. 2009a). 
Previous studies in our laboratory revealed that the use of fermentation systems with immobilized cells of $A$. japonicus was able to provide better FOS production results than free cell systems, which was considered an important advantage since the immobilized cells could be easily separated from the broth and reutilized in subsequent fermentation processes, decreasing the costs and time required for the inoculum preparation (Mussatto et al. 2009b). Based on these results, assays under solid-state fermentation (SSF) conditions were carried out, and this system was demonstrated to be an excellent alternative to improve the FOS and FFase production by $A$. japonicus when compared to batch submerged fermentation (Mussatto and Teixeira 2010). Among the materials tested as support for cell immobilization, coffee silverskin (CS, the outer casing of the seed separated during bean roasting), which is one of the most abundant coffee industry residues (Mussatto et al. 2011), was selected due to its great potential to immobilize cells as well as to serve as nutrient source for the microorganism.

Although the productions of FOS and FFase have been continuously increased through the fermentation systems previously evaluated (Mussatto et al. 2009b; Mussatto and Teixeira 2010), our former SSF study was not performed under optimized fermentation conditions, and it is well known that the establishment of the process conditions is of great importance to increase the product formation during SSF. Several recent studies on the production of different value-added products report maximization of the product formation when the SSF conditions were established (Xiong et al. 2007; Imandi et al. 2008; Mukherjee et al. 2008; Reddy et al. 2008; Liu et al. 2009). The present study aimed to establish the conditions of temperature, moisture content, and inoculum rate, to be employed during SSF using CS as solid support and nutrient source, in order to maximize the formation of FOS and FFase by A. japonicus. Experimental assays were planned according to a $2^{3}$ central composite design, and the conditions able to maximize the responses were defined by response surface methodology.

\section{Materials and Methods}

\section{Chemicals}

All the chemicals used were of analytical grade. FOS standards 1-kestose, 1-nystose, and 1- $\beta$-fructofuranosyl nystose were purchased from Wako Chemicals GmbH (Neuss, Germany).

Microorganism and Cultivation Conditions

A. japonicus ATCC 20236 was the fungal strain used in the experiments. The strain was maintained at $4{ }^{\circ} \mathrm{C}$ on Petri plates containing potato dextrose agar (PDA). For the production of spores, the fungus was grown on PDA medium at $28-30{ }^{\circ} \mathrm{C}$ for $7-8$ days. A concentrated suspension of spores was then prepared by scraping the spores from the PDA plates with a $0.1 \%(w / v)$ solution of Tween 80 sterilized by autoclaving at $121{ }^{\circ} \mathrm{C}$ for $20 \mathrm{~min}$. The number of spores in the suspension was determined by counting in a Neubauer chamber, and the volume needed to give the desired initial spore concentration in the fermentation medium was calculated.

\section{Solid Support and Fermentation Conditions}

CS was supplied by NovaDelta-Comércio e Indústria de Cafés S.A. (Campo Maior, Portugal). The material consisted of particles of approximately $3 \times 3 \mathrm{~mm}$ (length $\times$ width) in size and contained about $8 \%$ moisture content. To be used in the fermentation experiments, CS was sterilized by autoclaving at $121^{\circ} \mathrm{C}$ for $20 \mathrm{~min}$.

Fermentation assays were performed in $130-\mathrm{ml}$ glass flasks containing $2.5 \mathrm{~g}$ of sterilized CS. CS was moistened with a $240-\mathrm{g} / 1$ sucrose solution (autoclaved at $112{ }^{\circ} \mathrm{C}$ for $15 \mathrm{~min}$ ) to attain 60,70 , or $80 \%$ moisture content and was inoculated with the required volume of the concentrated spore suspension in order to obtain $2 \times 10^{5}, 2 \times 10^{6}$, or $2 \times$ $10^{7}$ spores/gram dry material. The inoculated material was mixed for a better distribution of the sucrose solution and spore suspension to the CS particles. The inoculated flasks were closed with aluminum foil and statically incubated at 26,30 , or $34{ }^{\circ} \mathrm{C}$ for $20 \mathrm{~h}$. The conditions used in each experimental assay were combined according to the $2^{3}$ central composite design presented in Table 1.

\section{Sampling and Analytical Determinations}

Samples (as the total content of each flask) were collected at $10,13,16$, and $20 \mathrm{~h}$ of fermentation. For the fermented broth extraction, $2 \mathrm{ml}$ of ultrapure water was added to the fermented material, which was then filtrated through a 0.22$\mu \mathrm{m}$ cellulose acetate membrane and used for determination of the sucrose and FOS concentrations, and FFase activity.

The concentrations of 1-kestose, 1-nystose, 1- $\beta$-fructosyl nystose, sucrose, fructose, and glucose were determined by high performance liquid chromatography (HPLC) using an equipment LC-10 A (Jasco, Japan) with a Prevail Carbohydrate ES column $(5 \mu \mathrm{m}, 250 \times 4.6 \mathrm{~mm}$, Alltech) at room temperature and a refractive index (RI) detector. The response of the RI detector was recorded and integrated using the Star Chromatography Workstation software (Varian). A mixture of acetonitrile and $0.04 \%$ ammonium hydroxide in water $(70 / 30 \mathrm{v} / \mathrm{v})$ was used as mobile phase at a flow rate of $1.0 \mathrm{ml} / \mathrm{min}$. The concentrations of sugars and FOS were determined from standard curves made with known concentrations of each compound. The sum of the 
Table 1 Experimental conditions and responses obtained during solid-state fermentation with $A$. japonicus using coffee silverskin as solid matrix

$T$ temperature (in degrees Celsius), $M$ moisture content (in percent), $I$ inoculum rate (in spores/gram dry substrate), FOS total concentration of fructooligosaccharides (in grams per liter), $t_{F O S}$ time where the maximum FOS production was achieved (in hours), FFase enzymatic activity of the $\beta$ fructofuranosidase enzyme (in units per milliliter), $t_{\text {FFase }}$ time where the maximum FFase production was achieved (in hours)

\begin{tabular}{|c|c|c|c|c|c|c|c|}
\hline \multirow[t]{2}{*}{ Assay } & \multicolumn{3}{|c|}{ Process variables (real and (coded) values) } & \multicolumn{4}{|l|}{ Responses } \\
\hline & $T$ & $M$ & $I$ & FOS & $t_{\mathrm{FOS}}$ & FFase & $t_{\mathrm{FFase}}$ \\
\hline 1 & $26(-1)$ & $60(-1)$ & $2 \times 10^{5}(-1)$ & $2.4 \pm 0.1$ & 20 & $11.41 \pm 0.25$ & 10 \\
\hline 2 & $34(+1)$ & $60(-1)$ & $2 \times 10^{5}(-1)$ & $48.9 \pm 0.3$ & 20 & $4.31 \pm 0.09$ & 20 \\
\hline 3 & $26(-1)$ & $80(+1)$ & $2 \times 10^{5}(-1)$ & $0 \pm 0$ & 20 & $2.51 \pm 0.06$ & 13 \\
\hline 4 & $34(+1)$ & $80(+1)$ & $2 \times 10^{5}(-1)$ & $131.8 \pm 2.6$ & 20 & $28.45 \pm 0.60$ & 20 \\
\hline 5 & $26(-1)$ & $60(-1)$ & $2 \times 10^{7}(+1)$ & $208.8 \pm 4.1$ & 20 & $51.55 \pm 1.25$ & 20 \\
\hline 6 & $34(+1)$ & $60(-1)$ & $2 \times 10^{7}(+1)$ & $114.8 \pm 2.5$ & 13 & $46.57 \pm 1.10$ & 13 \\
\hline 7 & $26(-1)$ & $80(+1)$ & $2 \times 10^{7}(+1)$ & $173.7 \pm 3.4$ & 20 & $51.70 \pm 1.42$ & 20 \\
\hline 8 & $34(+1)$ & $80(+1)$ & $2 \times 10^{7}(+1)$ & $101.8 \pm 2.2$ & 10 & $57.25 \pm 1.16$ & 13 \\
\hline 9 & $26(-1)$ & $70(0)$ & $2 \times 10^{6}(0)$ & $36.8 \pm 0.7$ & 20 & $21.85 \pm 0.48$ & 16 \\
\hline 10 & $34(+1)$ & $70(0)$ & $2 \times 10^{6}(0)$ & $128.3 \pm 2.2$ & 20 & $27.10 \pm 0.65$ & 16 \\
\hline 11 & $30(0)$ & $60(-1)$ & $2 \times 10^{6}(0)$ & $164.4 \pm 3.1$ & 16 & $54.54 \pm 1.25$ & 20 \\
\hline 12 & $30(0)$ & $80(+1)$ & $2 \times 10^{6}(0)$ & $112.4 \pm 2.4$ & 20 & $48.64 \pm 1.07$ & 20 \\
\hline 13 & $30(0)$ & $70(0)$ & $2 \times 10^{5}(-1)$ & $92.9 \pm 1.8$ & 20 & $25.38 \pm 0.54$ & 20 \\
\hline 14 & $30(0)$ & $70(0)$ & $2 \times 10^{7}(+1)$ & $149.3 \pm 3.0$ & 10 & $53.93 \pm 1.19$ & 13 \\
\hline 15 & $30(0)$ & $70(0)$ & $2 \times 10^{6}(0)$ & $163.8 \pm 3.3$ & 13 & $61.73 \pm 1.33$ & 16 \\
\hline 16 & $30(0)$ & $70(0)$ & $2 \times 10^{6}(0)$ & $162.9 \pm 3.0$ & 13 & $65.82 \pm 1.46$ & 16 \\
\hline 17 & $30(0)$ & $70(0)$ & $2 \times 10^{6}(0)$ & $164.2 \pm 3.2$ & 13 & $65.27 \pm 1.54$ & 16 \\
\hline 18 & $30(0)$ & $70(0)$ & $2 \times 10^{6}(0)$ & $155.5 \pm 3.1$ & 13 & $63.64 \pm 1.40$ & 16 \\
\hline
\end{tabular}

concentrations of 1-kestose, 1-nystose, and 1- $\beta$-fructosyl nystose represented the total FOS content in the samples.

The FFase activity was determined by measuring the amount of glucose produced from sucrose. The reaction mixture contained $100 \mathrm{ml}$ of the crude FFase extract, $300 \mathrm{mmol}$ of sucrose, and $50 \mathrm{mmol}$ of sodium acetate buffer $(\mathrm{pH} 5.0)$ in a total volume of $1 \mathrm{ml}$. After incubation for $20 \mathrm{~min}$ at $30{ }^{\circ} \mathrm{C}$, the reaction was stopped by heating for $5 \mathrm{~min}$ at $100{ }^{\circ} \mathrm{C}$. After cooling, the amount of glucose released into the supernatant was measured by HPLC. One unit (U) of FFase activity was defined as the amount of enzyme required to release $1 \mu \mathrm{mol}$ of glucose per minute, from sucrose under the above conditions (Mussatto et al. 2009b).

The results obtained in the analyses were calculated taking into account only the moisture content present in the material, i.e., being corrected by the dilution caused during the water addition to extract the fermented broth.

Fermentative Parameter Calculation and Statistical Analysis

FOS yield $\left(Y_{\mathrm{P} / \mathrm{S}}\right.$, percent $\left.w / w\right)$ was determined by the ratio between total FOS (in grams per liter) and initial sucrose (in grams per liter); while the FOS volumetric productivity $\left(Q_{\mathrm{P}}\right.$, in grams per liter per hour) was calculated by the ratio between total FOS (in grams per liter) and fermentation time (in hours). The statistical significance of the variables (temperature, moisture content, and inoculum rate) on the production of FOS and FFase was determined by using the softwares Statistica version 8.0 and Design Expert version 7.0 .

\section{Results and Discussion}

\section{FOS Production}

FOS production to each fermentation condition is shown in Table 1. It can be observed that, in the range of values studied, the variables strongly affected the FOS production, which varied between 0 (assay 3) and $208.8 \mathrm{~g} / 1$ (assay 5). According to the statistical analysis of these results, the moisture content had no significant influence $(p<0.05)$ on FOS production, but the temperature and inoculum rate showed significant effects on this response. Figure 1 clearly shows the effects of the temperature and inoculum rate on the production of FOS. The highest effect of the temperature was observed when using the lowest inoculum rate; however, for all the inoculum rates studied, the increase in temperature favored the production of FOS but up to a certain limit, after which the FOS production was negatively affected. Numerically, temperatures between 26 and $30{ }^{\circ} \mathrm{C}$ favored the production of FOS, while temperatures between 30 and $34{ }^{\circ} \mathrm{C}$ negatively affected the formation of this product. The effect of the inoculum rate on FOS production was also more significant under the lowest temperatures 
(Fig. 1). In this case, the FOS production was maximized when using the inoculum of approximately $2 \times 10^{7}$ spores/ gram dry material. Lower values of inoculum rate significantly affected the formation of FOS.

An equation able to predict the concentration of FOS by using moisture content $(M)$, inoculum rate $(I)$, and temperature $(T)$ in the same range of values evaluated in the present study was established (Eq. 1, coded values of the variables). The predominant effects of the temperature and inoculum rate on FOS production are evident in this equation. It is also important to emphasize that the variable moisture content, as well as the quadratic term of the variable inoculum rate, could be excluded from this equation without decreasing the value of the coefficient of determination $\left(R^{2}=0.86\right)$, demonstrating again that such variables did not have significant influence on FOS production.

$$
\begin{aligned}
\mathrm{FOS}(\text { in grams per liter })= & 145.68+10.39 T \\
& -50.95 T^{2}+47.24 I \\
& +13.43 T \times M-43.03 T \\
& \times I-16.08 M \times I
\end{aligned}
$$

Figure 2 shows the FOS yield $\left(Y_{\mathrm{P} / \mathrm{S}}\right)$ and productivity $\left(Q_{\mathrm{P}}\right)$ obtained for each fermentation condition. Since the FOS production strongly varied for each experimental assay, the values of these fermentative parameters presented also great variations. However, most of the experiments gave an FOS yield similar to or higher than the values usually

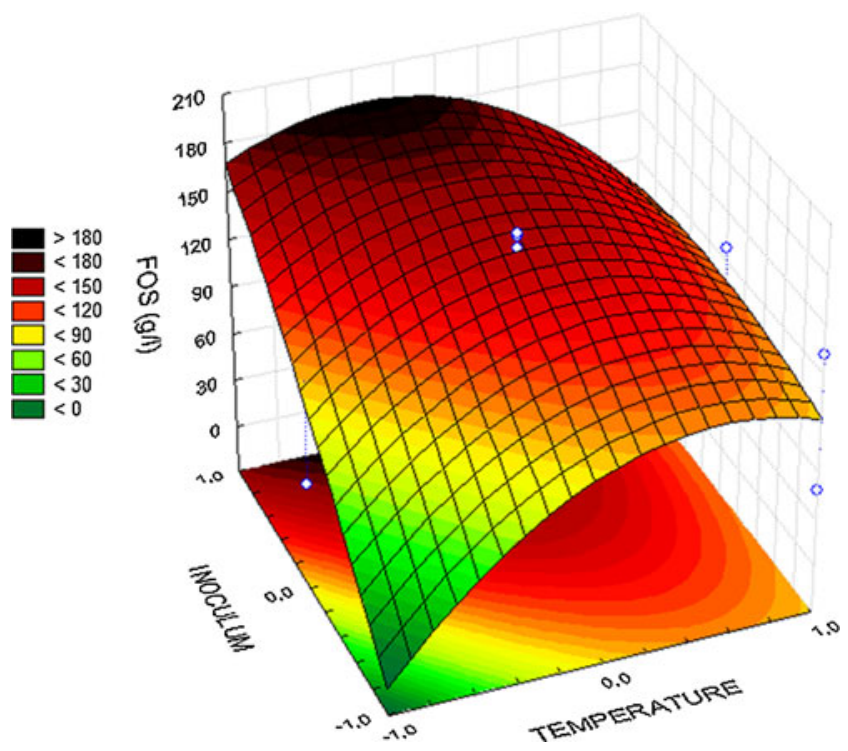

Fig. 1 Response surface representing the variations of FOS concentration according to the conditions of temperature and inoculum rate used during the solid-state fermentation. The levels of the variables are presented in the coded form $(-1,0,+1)$, which correspond to 26,30 , and $34{ }^{\circ} \mathrm{C}$ for the temperature and $2 \times 10^{5}, 2 \times 10^{6}$, and $2 \times 10^{7}$ spores/ gram dry material for the inoculum rate, respectively
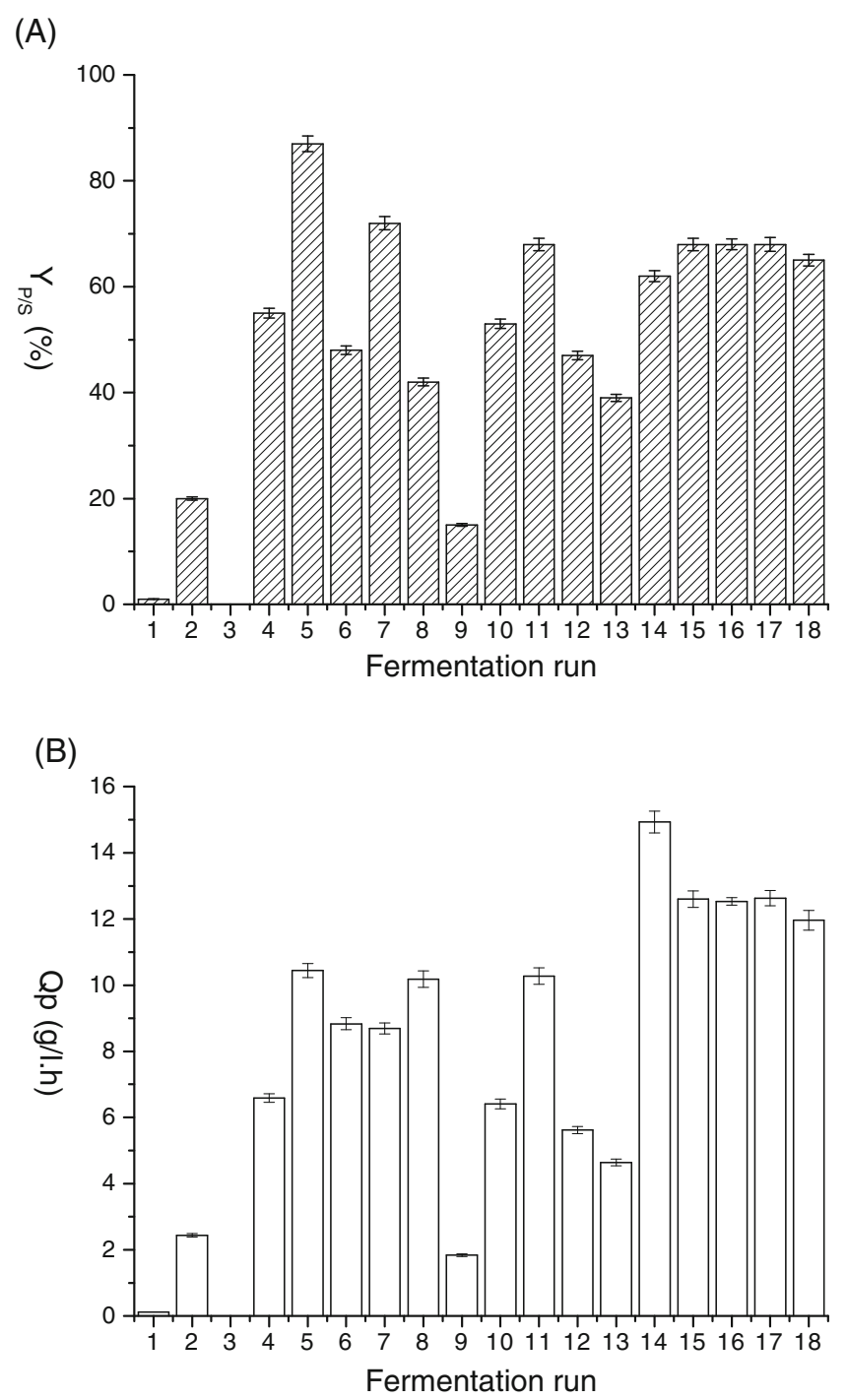

Fig. 2 Values of the fermentative parameters obtained during the production of FOS by solid-state fermentation. $Y_{P / S}$ FOS yield (in grams FOS per gram sucrose, in percent), $Q_{P}$ FOS productivity (in grams per liter per hour). The fermentation runs correspond to the conditions described in Table 1

obtained on an industrial scale (55-60 \%) (Yun 1996; Nishizawa et al. 2001). The values of $Y_{\mathrm{P} / \mathrm{S}}$ obtained in the present study can also be compared well with others reported in the literature for FOS production by different fungal strains (Table 2). Besides the elevated FOS yields, this study provided also high values of FOS productivity. Processes that allow obtaining the product with elevated productivity are strongly desired in an industrial point of view, since they make possible the reduction of operational costs.

Another important aspect to be detached is that the FOS obtained under the best fermentation condition was a mixture of $67 \% 1$-kestose and $33 \%$ of 1-nystose. It is known that increasing the length of the fructose chain decreases the 
Table 2 Fructooligosaccharides yield $\left(Y_{\mathrm{P} / \mathrm{S}}\right)$ obtained by fermentation with different fungal strains

\begin{tabular}{llll}
\hline Fungal strain & $\begin{array}{l}Y_{\mathrm{P} / \mathrm{S}} \\
(\%)\end{array}$ & $\begin{array}{l}\text { Time } \\
(\mathrm{h})\end{array}$ & Reference \\
\hline $\begin{array}{l}\text { Aspergillus oryzae CFR } \\
\quad 202\end{array}$ & 56 & 36 & Sangeetha et al. (2005) \\
$\begin{array}{l}\text { Aspergillus sp. N74 } \\
\text { Aspergillus niger AS 0023 }\end{array}$ & $50-53$ & 5.3 & Sánchez et al. (2010) \\
$\begin{array}{l}\text { Aureobasidium pullulans } \\
\text { sp. }\end{array}$ & 70 & 4.0 & L'Hocine et al. (2000) \\
$\begin{array}{l}\text { Penicillium citrinum } \\
\begin{array}{l}\text { Penicillium expansum } \\
\text { MUM 02.14 }\end{array}\end{array}$ & 55 & 24 & Madlová et al. (1999) \\
$\begin{array}{l}\text { Aspergillus japonicus } \\
\text { ATCC 20236 }\end{array}$ & 87 & 36 & Prata et al. (2010) \\
\hline
\end{tabular}

sweetening power of the FOS (Spiegel 1994; Cruz et al. 1998). In addition, FOS with a low degree of polymerization (DP) has better therapeutic properties than those with high DP (Sánchez et al. 2008). Such facts allow us to conclude that the FOS produced in the present study could be of value for application as a sweetener product for therapeutical purposes.

In brief, the production of FOS was maximized when the SSF was performed between 26 and $30^{\circ} \mathrm{C}$, with the support material inoculated with $2 \times 10^{7}$ spores/gram substrate. Particularly, the maximum concentration $(208.8 \mathrm{~g} / \mathrm{l})$ was achieved when using CS moistened to $60 \%$, inoculated with $2 \times 10^{7}$ spores/gram substrate at $26{ }^{\circ} \mathrm{C}$. These results are higher than those previously obtained under no optimized SSF conditions using CS and the same fungal strain (Mussatto and Teixeira 2010). In that study, a FOS productivity of $8.05 \mathrm{~g} / \mathrm{l} \mathrm{h}$ was achieved, while in the present study, this value was $30 \%$ higher $(10.44 \mathrm{~g} / \mathrm{l} \mathrm{h})$. Moreover, the FOS yield obtained in that study corresponded to $70 \%$ of the value obtained here. These results confirm the importance of establishing the process conditions to maximize the product formation. Additionally, the best FOS production results obtained in the present study are also higher than those achieved by batch submerged fermentation under no optimized process conditions with cells of $A$. japonicus immobilized on CS, which gave $Y_{\mathrm{P} / \mathrm{S}}$ and $Q_{\mathrm{P}}$ values of $65 \%$ and $5.60 \mathrm{~g} / 1 \mathrm{~h}$, respectively (Mussatto et al. 2009b). When comparing these two fermentation systems (submerged and solid-state), the most significant improvement was observed on FOS productivity, which was increased almost two times $(5.60$ to $10.44 \mathrm{~g} / \mathrm{h})$. The productivity increase is in fact considered an important advantage of SSF processes when compared to batch submerged fermentation systems (Martins et al. 2011).

In a recent study, Jung et al. (2011) obtained much higher FOS productivity $(180 \mathrm{~g} / \mathrm{l} \mathrm{h})$ by continuous submerged fermentation with Aureobasidium pullulans in a plant-scale reactor. Although the productivity value of the present study was much lower than that achieved by Jung and coworkers, our result is also of interest due to several advantages that solid-state fermentation systems present when compared to submerged fermentation systems (Martins et al. 2011). For example, the reutilization of low-cost agricultural and agroindustrial residues as substrates and/or nutrient sources made it possible to reduce the capital and operating costs for FOS production and contributes, at the same time, for the valorization of these wastes. The low water volume in SSF has also a large impact on the economy of the process mainly due to the smaller reactor sizes that are required, reduced downstream processing, reduced stirring, and lower sterilization costs (Martins et al. 2011).

\section{FFase Production}

Enzymatic activity of FFase also strongly varied according to the conditions used during SSF (Table 1). Similar to the production of FOS, temperature and inoculum rate were the variables with the highest influence on this response, while the moisture content did not show a significant effect $(p<0.05)$. High FFase activity is very important to obtain elevated production of FOS (Chen and Liu 1996), and this fact would explain the similar effects of the variables on both the responses. Figure 3 reveals that when the values of temperature and inoculum rate were increased, the FFase activity was improved but up to a certain limit after which the values of

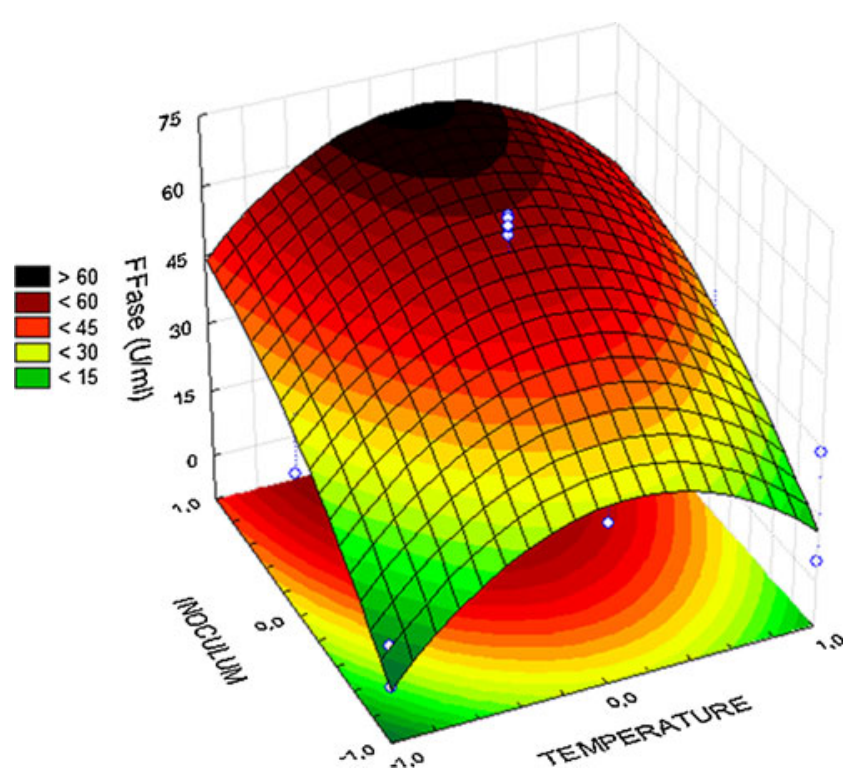

Fig. 3 Response surface representing the variations of FFase activity according to the conditions of temperature and inoculum rate used during the solid-state fermentation. The levels of the variables are presented in the coded form $(-1,0,+1)$, which correspond to 26,30 , and $34{ }^{\circ} \mathrm{C}$ for the temperature and $2 \times 10^{5}, 2 \times 10^{6}$, and $2 \times 10^{7}$ spores/ gram dry material for the inoculum rate, respectively 
enzymatic activity were negatively affected. This kind of behavior demonstrates that the conditions tested for the variables were suitable to define the point where the response could be maximized. Maximum values of FFase (average of $64.12 \mathrm{U} / \mathrm{ml}$ ) were achieved when using $30^{\circ} \mathrm{C}, 2 \times 10^{6}$ spores/ gram dry material, and $70 \%$ moisture content (conditions of assays $15-18$, Table 1 ).

An equation able to predict the FFase activity according to the conditions of temperature $(T)$, inoculum rate $(I)$, and moisture content $(M)$, in the same range of values studied here, was established (Eq. 2, coded values of the variables). This equation also reveals that the effects of the temperature and inoculum rate were the most important affecting this response. Similar to the analysis for FOS production, it was also possible to eliminate the effects of the variable moisture content and the quadratic term of the inoculum rate from the equation without decreasing the value of the coefficient of determination $\left(R^{2}=0.86\right)$.

FFase(in units per milliliter)

$$
\begin{aligned}
= & 54.87+2.47 T-24.60 T^{2}+18.89 I+5.45 T \\
& \times M-2.28 T \times I-0.55 M \times I
\end{aligned}
$$

The maximum value of FFase achieved in the present study represents an important improvement when compared to the results previously obtained without optimization of the process variables. With an enzymatic productivity of $4 \mathrm{U} / \mathrm{ml} \mathrm{h}$, the results maximized here represent an improvement of 2.7-fold when compared to the FFase productivity obtained in our previous study of SSF using CS as solid matrix and the same fungal strain (Mussatto and Teixeira 2010).

Simultaneous Maximization of FOS and FFase Production

As previously discussed, FOS production was maximized when the SSF was performed at $26^{\circ} \mathrm{C}$, using CS moistened to $60 \%$ and inoculated with $2 \times 10^{7}$ spores/gram dry substrate. However, FFase activity was maximized at $30{ }^{\circ} \mathrm{C}$, using $70 \%$ moisture content and $2 \times 10^{6}$ spores/gram dry substrate. From an industrial point of view, it would be very interesting to define a process condition able to maximize the formation of both products, simultaneously. Based on this fact, an optimization study was performed with the objective of establishing such fermentation conditions. Since the moisture content did not show significant effect on the responses, the value of this variable was fixed in the lowest evaluated value ( $60 \%)$, and only the temperature and inoculum rate were taken into account in this step of the study.

A graphical optimization based on an overlaying of the curves describing the FOS and FFase variations according to the temperature and inoculum rate variations was performed. In the obtained graph (Fig. 4), the dark region corresponds to the region where the values of FOS and FFase may be simultaneously maximized, taking into account the criteria imposed: FOS concentration higher than $180 \mathrm{~g} / \mathrm{l}$ and FFase activity higher than $60 \mathrm{U} / \mathrm{ml}$. Inside this region, several combinations between temperature and inoculum rate were able to provide FOS and FFase results higher than the proposed criteria. A point where both responses were maximized was detached by the flag. According to this analysis, it is possible to obtain $206 \mathrm{~g} /$ 1 of FOS and a FFase activity of $65.8 \mathrm{U} / \mathrm{ml}$ by performing the SSF at $28^{\circ} \mathrm{C}$ with an inoculum rate of $1.7 \times 10^{7}$ spores/ gram dry material.

\section{Conclusions}

FOS and FFase production by SSF with $A$. japonicus using coffee silverskin as solid matrix and nutrient source was maximized by establishing the best conditions of temperature, inoculum rate, and moisture content to be used during the fermentation. The results obtained under these selected fermentation conditions were significantly higher than those previously found under no optimized conditions. The next step of this study will be focused on the evaluation of strategies for purification of both products from the fermented

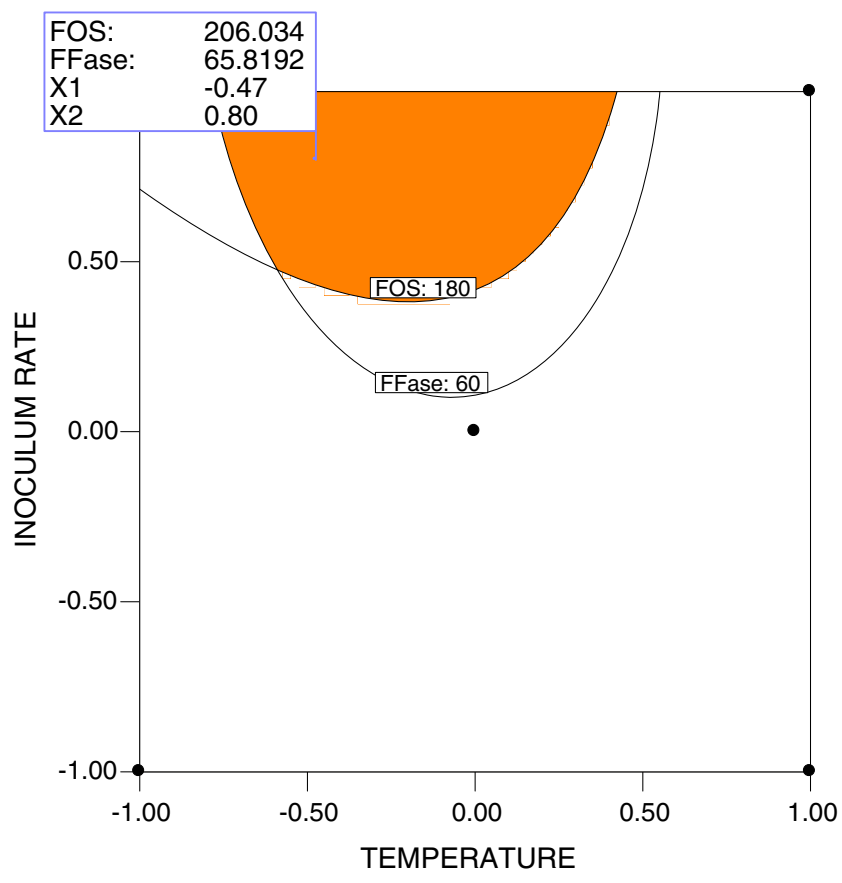

Fig. 4 Region where the results of FOS and FFase production can be simultaneously maximized, as a function of the initial temperature and inoculum rate used during the solid-state fermentation. The graphic was obtained by overlay plots of the two responses evaluated (FOS and FFase) 
broth. The scale-up of this fermentation process will also be the subject of our future works.

Acknowledgments This work was supported by grant SFRH/BPD/ 38212/2007 from the FCT (Portuguese Foundation for Science and Technology).

\section{References}

Chen, W.-C., \& Liu, C.-H. (1996). Production of $\beta$-fructofuranosidase by Aspergillus japonicus. Enzyme and Microbial Technology, 18, $153-160$

Chien, C.-S., Lee, W.-C., \& Lin, T.-J. (2001). Immobilization of Aspergillus japonicus by entrapping cells in gluten for production of fructooligosaccharides. Enzyme and Microbial Technology, 29, 252-257.

Cruz, R., Cruz, V. D., Belini, M. Z., Belote, J. G., \& Vieira, C. R. (1998). Production of fructooligosaccharides by the mycelia of Aspergillus japonicus immobilized in calcium alginate. Bioresource Technology, 65, 139-143.

Hartemink, R., Van Laere, K. M. J., \& Rombouts, F. M. (1997). Growth of enterobacteria on fructo-oligosaccharides. Journal of Applied Microbiology, 83, 367-374.

Hayashi, S., Yoshiyama, T., Fuji, N., \& Shinohara, S. (2000). Production of a novel syrup containing neofructooligosaccharides by the cells of Penicillium citrinum. Biotechnology Letters, 22, $1465-1469$.

Imandi, S. B., Bandaru, V. V. R., Somalanka, S. R., Bandaru, S. R., \& Garapati, H. R. (2008). Application of statistical experimental designs for the optimization of medium constituents for the production of citric acid from pineapple waste. Bioresource Technology, 99, 4445-4450.

Jung, K. H., Bang, S. H., Oh, T. K., \& Park, H. J. (2011). Industrial production of fructooligosaccharides by immobilized cells of Aureobasidium pullulans in a packed bed reactor. Biotechnology Letters, 33, 1621-1624.

L'Hocine, L., Wang, Z., Jiang, B., \& Xu, S. (2000). Purification and partial characterization of fructosyltransferase and invertase from Aspergillus niger AS0023. Journal of Biotechnology, 81, 73-84.

Liu, L., Lin, Z., Zheng, T., Lin, L., Zheng, C., Lin, Z., et al. (2009). Fermentation optimization and characterization of the laccase from Pleurotus ostreatus strain 10969. Enzyme and Microbial Technology, 44, 426-433.

Madlová, A., Antosová, M., Baráthová, M., Polakoviè, M., Stefuca, V., \& Báles, V. (1999). Screening of microorganisms for transfructosylating activity and optimization of biotransformation of sucrose to fructooligosaccharides. Chemical Papers, 53, 366-369.

Martins, S., Mussatto, S. I., Martínez-Avila, G., Montañez-Saenz, J., Aguilar, C. N., \& Teixeira, J. A. (2011). Bioactive phenolic compounds: production and extraction by solid-state fermentation. A review. Biotechnology Advances, 29, 365-373.

Mukherjee, S., Das, P., Sivapathasekaran, C., \& Sen, R. (2008). Enhanced production of biosurfactant by a marine bacterium on statistical screening of nutritional parameters. Biochemical Engineering Journal, 42, 254-260.

Mussatto, S. I., \& Mancilha, I. M. (2007). Non-digestible oligosaccharides: a review. Carbohydrate Polymers, 68, 587-597.

Mussatto, S. I., \& Teixeira, J. A. (2010). Increase in the fructooligosaccharides yield and productivity by solid-state fermentation with Aspergillus japonicus using agro-industrial residues as support and nutrient source. Biochemical Engineering Journal, 53, $154-157$.

Mussatto, S. I., Rodrigues, L. R., \& Teixeira, J. A. (2009a). $\beta$ Fructofuranosidase production by repeated batch fermentation with immobilized Aspergillus japonicus. Journal of Industrial Microbiology and Biotechnology, 36, 923-928.

Mussatto, S. I., Aguilar, C. N., Rodrigues, L. R., \& Teixeira, J. A. (2009b). Fructooligosaccharides and B-fructofuranosidase production by Aspergillus japonicus immobilized on lignocellulosic materials. Journal of Molecular Catalysis B: Enzymatic, 59, 76-81.

Mussatto, S. I., Machado, E. M. S., Martins, S., \& Teixeira, J. A. (2011). Production, composition, and application of coffee and its industrial residues. Food and Bioprocess Technology, 4, 661-672.

Nishizawa, K., Nakajima, M., \& Nabetani, H. (2001). Kinetic study on transfructosylation by $\beta$-fructofuranosidase from Aspergillus niger ATCC 20611 and availability of a membrane reactor for fructooligosaccharide production. Food Science and Technology Research, 7, 39-44.

Prata, M. B., Mussatto, S. I., Rodrigues, L. R., \& Teixeira, J. A. (2010). Fructooligosaccharide production by Penicillium expansum. Biotechnology Letters, 32, 837-840.

Reddy, L. V. A., Wee, Y.-J., Yun, J.-S., \& Ryu, H.-W. (2008). Optimization of alkaline protease production by batch culture of Bacillus sp. RKY3 through Plackett-Burman and response surface methodological approaches. Bioresource Technology, 99, 22422249.

Sánchez, O., Guio, F., Garcia, D., Silva, E., \& Caicedo, L. (2008). Fructooligosaccharides production by Aspergillus sp. N74 in a mechanically agitated airlift reactor. Food and Bioproducts Processing, 86, 109-115.

Sánchez, O. F., Rodriguez, A. M., Silva, E., \& Caicedo, L. A. (2010). Sucrose biotransformation to fructooligosaccharides by Aspergillus sp. N74 free cells. Food and Bioprocess Technology, 3, 662-673.

Sangeetha, P. T., Ramesh, M. N., \& Prapulla, S. G. (2005). Maximization of fructooligosaccharide production by two stage continuous process and its scale up. Journal of Food Engineering, $68,57-64$.

Spiegel, J. (1994). Safety and benefits of fructooligosaccharides as food ingredients. Food Technology, 48, 85-89.

Van den Heuvel, E. G. H. M., Muys, T., van Dokkum, W., \& Schaafsma, G. (1999). Oligofructose stimulates calcium absorption in adolescents. American Journal of Clinical Nutrition, 69, $544-548$.

Xiong, C., Jinhua, W., \& Dongsheng, L. (2007). Optimization of solidstate medium for the production of inulinase by Kluyveromyces S120 using response surface methodology. Biochemical Engineering Journal, 34, 179-184.

Yun, J. W. (1996). Fructooligosaccharides-occurrence, preparation, and application. Enzyme and Microbial Technology, 19, 107-117. 